\title{
The development of simple anthropometric measures to diagnose antiretroviral therapy- associated lipodystrophy in resource limited settings
}

Zulfa Abrahams ${ }^{1}$, Joel A Dave ${ }^{1}$, Gary Maartens ${ }^{2}$, Maia Lesosky ${ }^{3}$ and Naomi S Levitt ${ }^{1 *}$

\begin{abstract}
Background: Lipohypertrophy does not appear to be an adverse ART reaction while lipoatrophy is clearly associated with the use of stavudine (d4T) and zidovudine (AZT). In low and middle income countries d4T has only recently been phased out and AZT is still widely being used. Several case definitions have been developed to diagnose lipodystrophy, but none of them are generalizable to sub-Saharan Africa where black women have less visceral adipose tissue and more subcutaneous adipose tissue than white women. We aimed to develop a simple, objective measure to define lipoatrophy and lipohypertrophy by comparing patient report to anthropometric and dual-energy X-ray absorptiometry (DXA) -derived variables.
\end{abstract}

Methods: DXA and anthropometric measures were obtained in a cross sectional sample of black HIV-infected South African men $(n=116)$ and women $(n=434)$ on ART. Self-reported information on fat gain or fat loss was collected using a standard questionnaire. Receiver operating characteristic (ROC) curves were used to describe the performance of anthropometric and DXA-derived variables using patient reported lipoatrophy and lipohypertrophy as the reference standard.

Results: Lipoatrophy and lipohypertrophy were more common in women (25\% and 33\% respectively) than in men (10\% and 13\% respectively). There were insufficient numbers of men with DXA scans for meaningful analysis. The best predictors of lipoatrophy in women were the anthropometric variables tricep (AUC $=0.725)$ and thigh skinfold (AUC $=0.720)$ thicknesses; and the DXA-derived variables percentage lower limb fat (AUC $=0.705)$ and percentage lower limb fat/height (AUC = 0.713). The best predictors of lipohypertrophy in women were the anthropometric variable waist/hip ratio (AUC $=0.645$ ) and the DXA-derived variable percentage trunk fat/percentage limb fat (AUC $=0.647$ ).

Conclusions: We were able to develop simple, anthropometric measures for defining lipoatrophy and lipohypertrophy, using a sample of black HIV-infected South African women with DXA scans. This is of particular relevance in resource limited settings, where health professionals need simple and inexpensive methods of diagnosing patients with lipoatrophy and lipohypertrophy.

Keywords: HIV, Lipoatrophy, Lipohypertrophy, Lipodystrophy, DXA, Anthropometry, Sub-Saharan africa, Antiretroviral therapy

\footnotetext{
*Correspondence: Naomi.levitt@uct.ac.za

'Division of Diabetic Medicine and Endocrinology, Department of Medicine,

University of Cape Town, Cape Town, South Africa

Full list of author information is available at the end of the article
} 


\section{Background}

Antiretroviral therapy (ART) has significantly reduced the morbidity and mortality of people infected with HIV [1], however, long-term use of ART has been associated with a number of metabolic complications such as dysglycaemia, insulin resistance, dyslipidaemia and lipodystrophy [2]. Lipodystrophy is characterized by either subcutaneous fat loss (lipoatrophy), which is most noticeable in the face, limbs, and buttocks, or fat accumulation (lipohypertrophy) seen in the abdomen, breast or posterior neck, or a combination of both $[3,4]$.

Both subjective and objective methods have been used to diagnose lipodystrophy, resulting in a number of case definitions. The most widely used subjective methods of diagnosis are patient perception and report $[5,6]$, physician examination and report [7], and physician confirmation of patient report [8-11]. Objective measures include imaging by dual-energy $\mathrm{X}$-ray absorptiometry (DXA) $[6,12,13]$ and computed tomography (CT) scans $[12,14]$. These imaging measures are expensive and not widely available in resource limited settings. Anthropometric and DXA-derived variables have also been developed, in an attempt to provide standard measures of defining lipodystrophy [15-17]. Furthermore, criteria established to define lipodystrophy did not include data from any African country. These diagnostic criteria may not be generalizable to sub-Saharan Africans, as there are important ethnic differences in fat distribution, especially in black women who have less visceral adipose tissue and more subcutaneous adipose tissue than white women [18-20].

Lipohypertrophy does not appear to be an adverse ART reaction as participants on different ART drug regimens gained similar amounts of trunk fat over time [21]. Lipoatrophy, in contrast is clearly an adverse ART reaction. The use of stavudine (d4T) and zidovudine (AZT) is associated with subcutaneous fat loss and is partially reversed after changing to abacavir or tenofovir [21,22]. Lipoatrophy remains common in low and middle income countries where $\mathrm{d} 4 \mathrm{~T}$ has only recently been phased out and AZT is still widely used [23]. However, even if lipohypertrophy is not associated with ART, lipodystrophy, and lipoatrophy in particular, is independently associated with an increased risk of vascular disease [24,25]. Therefore recognising lipodystrophy is important to identify patients at risk for vascular disease so that screening can be targeted for other vascular risk factors, while recognising lipoatrophy is important so that $\mathrm{d} 4 \mathrm{~T}$ or AZT can be substituted.

The aim of our study was to develop a simple, objective measure to define lipoatrophy and lipohypertrophy by comparing patient report to anthropometric and DXA-derived variables in a sample of black South Africans on ART.

\section{Results}

Participant characteristics are presented in Table 1. The study sample consisted of 550 participants on ART. Based on patient report, 121 (22\%) had lipoatrophy and 157 (29\%) had lipohypertrophy. Both lipoatrophy and lipohypertrophy were significantly more common in females than in males $(p \leq 0.001)$. Participants with lipoatrophy had spent a significantly longer period of time on ART (25 vs. 17 months) and a longer time on d4T (15.5 vs. 13 months).

Anthropometric variables are shown separately for women and men (Tables 2 and 3 respectively). In women, all median skinfold measurements, with the exception of sub-scapular skinfold thickness, were significantly lower in participants with lipoatrophy compared with those without lipoatrophy. Measurements for waist circumference, waist/hip ratio and supra-iliac skinfold thickness were significantly higher in women with lipohypertrophy compared with those without lipohypertrophy. There were no statistically significant differences in anthropometric variables in males with and without lipoatrophy (Table 3). Males with lipohypertrophy had a significantly $(P=0.008)$ greater thigh circumference than those without (13.5 $\mathrm{mm}$ vs. $8.1 \mathrm{~mm}$ ).

DXA-derived measures are shown for women only (Table 4), as there were insufficient numbers of men with DXA scans for meaningful analysis. Women with lipoatrophy as well as those with lipohypertrophy, had significantly higher percentage trunk fat/lower limb fat and percentage trunk fat/total limb fat and significantly lower percentage lower limb fat/BMI. Women with lipoatrophy had significantly less percentage limb fat while women with lipohypertrophy had significantly more percentage trunk fat.

ROC curves for lipoatrophy and lipohypertrophy were generated and reported in female participants for anthropometric and DXA-derived variables with the highest AUC's (Figure 1). For lipoatrophy, the two anthropometric variables with the highest AUC were tricep skinfold thickness $(\mathrm{AUC}=0.725)$ and thigh skinfold thickness $(\mathrm{AUC}=$ 0.720 ) and for lipohypertrophy they were waist/hip ratio $(\mathrm{AUC}=0.645)$ and waist circumference $(\mathrm{AUC}=0.589)$. For lipoatrophy, the two DXA-derived variables with the highest AUC were the percentage of lower limb fat standardised to height $(\mathrm{AUC}=0.713)$ and percentage lower limb fat $(\mathrm{AUC}=0.705)$ and for lipohypertrophy they were percentage trunk fat/percentage total limb fat $(\mathrm{AUC}=$ 0.647 ) and percentage trunk fat/ percentage lower limb fat $(\mathrm{AUC}=0.646)$. An illustration of anthropometric and DXA-derived variables in females is shown in Figure 2.

Optimum cut-points for lipoatrophy and lipohypertrophy variables, based on likelihood ratios, were selected. Table 5 shows the sensitivity, specificity, likelihood ratios and predictive values for the two anthropometric and 
Table 1 Characteristics of participants on ART

\begin{tabular}{|c|c|c|c|c|c|c|}
\hline \multirow[b]{2}{*}{ Variable } & \multicolumn{2}{|c|}{ Lipoatrophy* } & \multirow[b]{2}{*}{ P-value ${ }^{* *}$} & \multicolumn{2}{|c|}{ Lipohypertrophy*** } & \multirow[b]{2}{*}{ P-value $* *$} \\
\hline & $\begin{array}{c}\text { With } \\
n=121 \\
\text { Median [IQR] }\end{array}$ & $\begin{array}{c}\text { Without } \\
n=429 \\
\text { Median [IQR] }\end{array}$ & & $\begin{array}{c}\text { With } \\
n=157 \\
\text { Median [IQR] }\end{array}$ & $\begin{array}{c}\text { Without } \\
n=393 \\
\text { Median [IQR] }\end{array}$ & \\
\hline Age & 34 [30-42] & $35[30-41]$ & 0.256 & $34[29-41]$ & $35[30-41]$ & 0.198 \\
\hline Current CD4 count & 397 [249-539] & 315 [218-481] & 0.023 & 389 [248-548] & 314 [220-481] & 0.015 \\
\hline Time on ART (months) & 25 [14-32] & 17 [10-27] & 0.001 & $20[12-31]$ & 17 [11-28] & 0.080 \\
\hline \multirow[t]{2}{*}{ Time on Stavudine (months) } & $15.5[10-26]$ & $13[8-19]$ & 0.004 & $13[8-21]$ & 13 [9-20] & 0.961 \\
\hline & n [\%] & n [\%] & & n [\%] & n [\%] & \\
\hline \multicolumn{7}{|l|}{ Sex } \\
\hline Males & 12 [10.34] & $104[89.66]$ & 0.001 & 15 [12.93] & $101[87.07]$ & $<0.001$ \\
\hline Females & 109 [25.12] & $325[74.88]$ & & $142[32.72]$ & $292[67.28]$ & \\
\hline \multicolumn{7}{|l|}{ Highest standard passed } \\
\hline No schooling & $6[18.8]$ & $26[81.3]$ & 0.289 & 9 [28.13] & $23[71.88]$ & 0.272 \\
\hline Primary school & $14[15.4]$ & $77[84.6]$ & & 20 [21.98] & $71[78.02]$ & \\
\hline Secondary school & $96[23.4]$ & 315 [76.6] & & $121[29.44]$ & $290[70.56]$ & \\
\hline Tertiary & $5[31.3]$ & 11 [68.8] & & 7 [43.75] & 9 [56.25] & \\
\hline \multicolumn{7}{|l|}{ ART Regimen } \\
\hline First-line & 99 [22.30] & 345 [77.70] & 0.730 & $130[29.28]$ & 314 [70.72] & 0.608 \\
\hline Second-line & 22 [20.75] & 84 [79.25] & & 27 [25.47] & 79 [74.53] & \\
\hline
\end{tabular}

*based on patient report, those with moderate or severe fat loss in 2 or more regions.

**Wilcoxon Rank-sum (Mann-Whitney) tests for continuous variables and chi-square tests for binary variables.

***based on patient report, those with moderate or severe fat gain in 2 or more regions.

DXA-derived variables with the highest AUC for lipoatrophy and lipohypertrophy at the optimum cut-points.

\section{Discussion}

We showed that simple anthropometric measures were at least as good as DXA-derived measures to diagnose lipoatrophy and lipohypertrophy in African women on ART. The best predictors of lipoatrophy in women were the anthropometric variables tricep and thigh skinfold thicknesses; and the DXA-derived variables percentage lower limb fat and percentage lower limb fat/height. The best predictors of lipohypertrophy in women were the anthropometric variable waist/hip ratio and the DXA-derived variable percentage trunk fat/percentage limb fat. Women with lipoatrophy had considerably smaller limb circumferences, limb skinfold thicknesses and lower percentages of limb fat than women without lipoatrophy, despite similar BMIs. Lipoatrophy and lipohypertrophy were both more common in women than in the small sample of men.

Previous studies, conducted in high-income countries, developed objective measures for lipodystrophy, thus combining lipoatrophic and lipohypertrophic individuals [15-17]. They proposed the use of fat mass ratio (FMR), defined as the ratio between the percentage of trunk fat mass and the percentage of lower-limb fat mass. We however sought to investigate lipoatrophy and lipohypertrophy as separate entities. Identification of lipoatrophy is important as it is an adverse antiretroviral drug reaction, which improves on switching antiretroviral drugs [21]. Although lipohypertrophy is thought to be a consequence of treating HIV infection rather than an adverse antiretroviral drug reaction [21], like lipoatrophy, it is associated with an increased risk of vascular disease [26] therefore it is worth identifying so that appropriate screening and prevention interventions can be implemented.

Despite the subjective nature of assessing lipoatrophy and lipohypertrophy by using patient self-report, previous studies have shown a strong correlation between patient and physician reported lipodystrophy scores [27-29]. In South Africa, as well as in many other African countries, nurses, rather than physicians, prescribe antiretroviral therapy and follow up patients. For these reasons we used patient self-report [5,6] as the reference measure to define lipoatrophy and lipohypertrophy.

Our study, like several others [11,21], showed a significant association between lipoatrophy and time on ART, and time on $\mathrm{d} 4 \mathrm{~T}$ in particular. As South Africa has only recently phased out $\mathrm{d} 4 \mathrm{~T}$, and $\mathrm{AZT}$ is still being used, it is not unexpected that a quarter of the women and a tenth of the men, had lipoatrophy. The prevalence of lipoatrophy found in this study is not easy to compare with other studies as studies from high-income countries 
Table 2 Anthropometric measurements of female participants on ART

\begin{tabular}{|c|c|c|c|c|c|c|}
\hline \multirow[b]{2}{*}{ Variable } & \multicolumn{2}{|c|}{ Lipoatrophy* } & \multirow[b]{2}{*}{ P-value** } & \multicolumn{2}{|c|}{ Lipohypertrophy*** } & \multirow[b]{2}{*}{ P-value** } \\
\hline & $\begin{array}{c}\text { With } \\
n=106 \\
\text { Median [IQR] }\end{array}$ & $\begin{array}{c}\text { Without } \\
n=312 \\
\text { Median [IQR] }\end{array}$ & & $\begin{array}{c}\text { With } \\
n=142 \\
\text { Median [IQR] }\end{array}$ & $\begin{array}{c}\text { Without } \\
n=292 \\
\text { Median [IQR] }\end{array}$ & \\
\hline Height (m) & $1.6[1.5-1.6]$ & $1.6[1.5-1.6]$ & 0.603 & $1.6[1.6-1.6]$ & $1.6[1.5-1.6]$ & 0.112 \\
\hline Weight (kg) & $65.4[56.0-74.5]$ & $68.1[58.9-80.9]$ & 0.019 & $69.5[60.7-80.4]$ & $67.1[57.6-79.3]$ & 0.127 \\
\hline BMI & $26.2[23.8-29.3]$ & $27.1[24.1-31.6]$ & 0.036 & $27.4[24.6-31.3]$ & $26.65[23.9-31.2]$ & 0.187 \\
\hline Sagittal Abdominal Diameter (cm) & $20.5[19.0-23.0]$ & $20.0[18.5-23.0]$ & 0.552 & $21[19-24]$ & 20 [18-23] & 0.004 \\
\hline \multicolumn{7}{|l|}{ Circumferences } \\
\hline Waist (cm) & 86.3 [79.5-96.3] & $87.0[78.5-97.0]$ & 0.704 & $90.7[80.3-98.5]$ & 86 [78.4-95] & 0.003 \\
\hline Hip (cm) & $98.0[92.0-104.0]$ & $102.0[95.0-112.0]$ & $<0.001$ & 100 [95-110] & $101[94-110]$ & 0.824 \\
\hline Waist/hip ratio & $0.90[0.83-0.94]$ & $0.85[0.80-0.90]$ & $<0.001$ & $0.89[0.83-0.93]$ & $0.84[0.79-0.90]$ & $<0.001$ \\
\hline Mid-upper arm (cm) & $27.0[25.0-29.0]$ & $29.0[26.5-32.0]$ & $<0.001$ & $28[26-32]$ & $28[26-32]$ & 0.789 \\
\hline Mid-thigh (cm) & 54.5 [51.0-59.0] & $57.0[53.0-63.0]$ & $<0.001$ & $56[52-61]$ & $57[52-63]$ & 0.589 \\
\hline \multicolumn{7}{|l|}{ Skinfolds } \\
\hline Bicep (mm) & $6.0[4.4-8.4]$ & $8.1[5.7-11.7]$ & $<0.001$ & $7.1[5.2-10.7]$ & $8[5.4-11.45]$ & 0.189 \\
\hline Tricep (mm) & $13.3[9.5-17.4]$ & 18.4 [13.6-26.0] & $<0.001$ & $16.2[12-22]$ & 18.3 [13-25.15] & 0.059 \\
\hline Abdomen (mm) & 20.4 [11.9-30.0] & $24.4[16.8-35.3]$ & 0.001 & 24.1 [15.9-35.8] & $23.6[15.0-31.2]$ & 0.210 \\
\hline Thigh (mm) & 23.8 [15.4-32.8] & $34.7[24.2-44.7]$ & $<0.001$ & 29.8 [20.5-42.5] & $32.0[22.5-43.5]$ & 0.359 \\
\hline Sub-Scapular (mm) & 16.9 [12.5-23.0] & $19.2[12.2-28.8]$ & 0.058 & 20 [14.8-29.4] & $18.5[11.7-27.1]$ & 0.050 \\
\hline Supra-iliac (mm) & $13.2[7.7-18.7]$ & $15.1[8.8-22.8]$ & 0.033 & $16.6[9.9-24.0]$ & $13.9[8.2-21.7]$ & 0.022 \\
\hline Calf (mm) & $10.8[8.0-17.5]$ & $17.5[12.2-24.2]$ & $<0.001$ & $15.6[9.2-21.3]$ & $17.3[11.4-23.6]$ & 0.061 \\
\hline
\end{tabular}

*based on patient report, those with moderate or severe fat loss in 2 or more regions.

**Wilcoxon Rank-sum (Mann-Whitney) tests for continuous variables and chi-square tests for binary variables.

***based on patient report, those with moderate or severe fat gain in 2 or more regions.

focussed on men [12,24], while most studies from Africa looked at the prevalence of lipodystrophy [30-32] rather than studying the two entities of lipoatrophy and lipodystrophy separately. Our finding that tricep skinfold thickness was a predictor of lipoatrophy is supported by other studies. George et al. [33], using a small sample of HIV-infected South Africans, found that after 2 years of exposure to ART, patients had significantly decreased tricep skinfold thicknesses. Similarly, a Ugandan study using a sample of HIV-infected men and women [32], found that decreased tricep skinfold thicknesses was associated with the use of AZT.

There were some limitations to our study. The cross sectional design, while allowing us to make associations, does not allow us to infer causality. With changes in fat distribution, repeated objective measures would have given us a better reference standard than patient report, even though patient report is commonly used $[5,6]$. We did not have enough men with lipoatrophy or lipohypertrophy, to explore predictive anthropometric and DXA-derived variables. Finally, the likelihood ratios for the most predictive anthropometric and DXA-derived variables were only weakly diagnostic of self-report lipoatrophy and lipohypertrophy. Future research of longitudinal studies in African cohorts, using changes in DXA-derived variables as the reference standard, is needed to confirm the value of anthropometric measures for the diagnosis of lipoatrophy and lipohypertrophy.

\section{Conclusion}

Using a large sample of black HIV-infected South African women who had DXA scans performed, we were able to develop anthropometric measures for defining lipoatrophy and lipohypertrophy. The development of anthropometric measures which admittedly needs training and well maintained skinfold callipers to ensure their accuracy, are of particular relevance in resource limited settings, where health professionals need simple and inexpensive methods of diagnosing patients with lipoatrophy and lipohypertrophy.

\section{Methods}

\section{Participants}

A convenience sample of HIV-infected black men and women presenting to ART clinics in Cape Town were selected. The recruitment procedure is described elsewhere [34]. The study sample comprised 116 male and 434 female participants on ART. At the time of the study 
Table 3 Anthropometric measurements of male participants on ART

\begin{tabular}{|c|c|c|c|c|c|c|}
\hline \multirow[b]{2}{*}{ Variable } & \multicolumn{2}{|c|}{ Lipoatrophy* } & \multirow[b]{2}{*}{ P-value** } & \multicolumn{2}{|c|}{ Lipohypertrophy*** } & \multirow[b]{2}{*}{ P-value ${ }^{* *}$} \\
\hline & $\begin{array}{c}\text { With } \\
n=12 \\
\text { Median [IQR] }\end{array}$ & $\begin{array}{c}\text { Without } \\
n=104 \\
\text { Median [IQR] }\end{array}$ & & $\begin{array}{c}\text { With } \\
n=15 \\
\text { Median [IQR] }\end{array}$ & $\begin{array}{c}\text { Without } \\
n=101 \\
\text { Median [IQR] }\end{array}$ & \\
\hline Height (m) & $1.7[1.6-1.7]$ & $1.7[1.6-1.7]$ & 0.942 & $1.7[1.6-1.8]$ & $1.7[1.7-1.7]$ & 0.954 \\
\hline Weight (kg) & $65.5[59.7-68.6]$ & $63.5[57.0-74.4]$ & 0.895 & $67.4[57.8-78.3]$ & $62.7[57.3-73.4]$ & 0.408 \\
\hline BMI & $23.3[20.2-23.9]$ & $22.4[20.6-25.2]$ & 0.772 & $23.6[21.1-25.5]$ & $22.3[20.5-24.8]$ & 0.324 \\
\hline Sagittal Abdominal Diameter (cm) & $17.0[16.0-19.5]$ & $18.0[17.0-20.0]$ & 0.384 & $17.0[16.0-22.0]$ & $18.0[17.0-20.0]$ & 0.967 \\
\hline \multicolumn{7}{|l|}{ Circumferences } \\
\hline Waist (cm) & $81.75[77-84.9]$ & $80.4[75.0-90.2]$ & 0.953 & $83.8[75.0-97.0]$ & $79.8[75.8-89.5]$ & 0.338 \\
\hline Hip (cm) & 90 [87-93.5] & $90.0[85.0-97.0]$ & 0.768 & 91.0 [85.0-97.0] & $90.0[85.0-96.0]$ & 0.556 \\
\hline Waist/hip ratio & $0.89[0.85-0.95]$ & $0.91[0.87-0.94]$ & 0.740 & $0.93[0.86-0.97]$ & $0.90[0.86-0.94]$ & 0.325 \\
\hline Mid-upper arm (cm) & $27.0[24-28.5]$ & $26.0[24.0-29.0]$ & 0.877 & $27.0[25.0-29.0]$ & $26.0[24.0-29.0]$ & 0.817 \\
\hline Mid-thigh (cm) & $50.5[43.5-52.5]$ & $49.0[46.0-54.0]$ & 0.401 & 49.0 [46.0-56.0] & $49.0[46.0-54.0]$ & 0.567 \\
\hline \multicolumn{7}{|l|}{ Skinfolds } \\
\hline Bicep (mm) & $3.9[3.4-4.2]$ & $3.5[3.0-4.5]$ & 0.329 & $4.1[3.2-4.8]$ & $3.5[3.0-4.3]$ & 0.180 \\
\hline Tricep (mm) & $6.8[5.6-8.2]$ & $6.4[5.1-9.3]$ & 0.921 & $8.4[5.0-11.4]$ & $6.4[5.1-8.7]$ & 0.444 \\
\hline Abdomen (mm) & 13.5 [10.5-16.9] & $12.3[8.5-30.1]$ & 1.00 & $15.8[9.3-28.2]$ & $12.3[8.5-18.1]$ & 0.309 \\
\hline Thigh (mm) & $8.4[7.2-14.8]$ & $8.5[6.0-12.4]$ & 0.490 & $13.5[8.4-21.1]$ & $8.1[6.0-11.3]$ & 0.008 \\
\hline Sub-Scapular (mm) & $9.4[6.5-13.2]$ & $8.3[6.3-13.4]$ & 0.605 & $10.5[5.7-18.0]$ & $8.2[6.5-11.1]$ & 0.770 \\
\hline Supra-iliac (mm) & $6.3[4.4-6.8]$ & $6.2[4.9-9.4]$ & 0.196 & $6.4[4.7-12.1]$ & $6.2[4.9-8.5]$ & 0.934 \\
\hline Calf (mm) & $5.5[4.8-9.0]$ & $5.8[4.4-8.2]$ & 0.739 & $6.8[5.4-10.5]$ & $5.5[4.4-7.7]$ & 0.094 \\
\hline
\end{tabular}

*based on patient report, those with moderate or severe fat loss in 2 or more regions.

**Wilcoxon Rank-sum (Mann-Whitney) tests for continuous variables and chi-square tests for binary variables.

***based on patient report, those with moderate or severe fat gain in 2 or more regions.

Table 4 DXA-derived measurements of female participants on ART

\begin{tabular}{|c|c|c|c|c|c|c|}
\hline \multirow[b]{2}{*}{ Variable } & \multicolumn{2}{|c|}{ Lipoatrophy* } & \multirow[b]{2}{*}{ P-value** } & \multicolumn{2}{|c|}{ Lipohypertrophy*** } & \multirow[b]{2}{*}{ P-value** } \\
\hline & $\begin{array}{c}\text { With } \\
n=29 \\
\text { Median [IQR] }\end{array}$ & $\begin{array}{c}\text { Without } \\
n=143 \\
\text { Median [IQR] }\end{array}$ & & $\begin{array}{c}\text { With } \\
n=46 \\
\text { Median [IQR] }\end{array}$ & $\begin{array}{c}\text { Without } \\
n=126 \\
\text { Median [IQR] }\end{array}$ & \\
\hline \multicolumn{7}{|l|}{ DXA-derived measures } \\
\hline Arm fat (\%) & $37.4[30.8-44.1]$ & $38.3[31.8-47.1]$ & 0.380 & 39.8 [31.5-48.3] & $38.1[31.7-45.1]$ & 0.319 \\
\hline Lower limb fat (\%) & $37.6[31.5-40.6]$ & $43.4[36.6-49.7]$ & 0.001 & 39.2 [33.3-49.7] & 41.8 [36.3-48.8] & 0.761 \\
\hline Trunk fat (\%) & 34.7 [29.9-38.0] & $35.1[27.9-43.1]$ & 0.719 & $37.9[30.7-45.3]$ & $34.4[26.6-40.4]$ & 0.019 \\
\hline Lower limb fat/ht (\%) & $23.6[19.7-25.4]$ & $27.4[23.4-31.5]$ & 0.001 & $25.4[21.9-31.1]$ & $26.5[23.2-29.7]$ & 0.631 \\
\hline Total limb fat/ht (\%) & $22.7[20.8-27.0]$ & 25.4 [22.0-29.9] & 0.015 & $25.4[20.8-31.1]$ & $25.2[21.8-29.1]$ & 0.825 \\
\hline Lower limb fat/BMI (\%) & $1.3[1.2-1.7]$ & $1.6[1.3-1.8]$ & 0.049 & $1.4[1.2-1.6]$ & $1.6[1.3-1.8]$ & 0.019 \\
\hline Total limb fat/BMI (\%) & $1.3[1.3-1.6]$ & $1.5[1.3-1.6]$ & 0.193 & $1.3[1.2-1.5]$ & $1.5[1.3-1.7]$ & 0.006 \\
\hline Trunk fat/lower limb fat (\%) & $0.94[0.76-1.15]$ & $0.83[0.66-0.96]$ & 0.017 & $0.93[0.80-1.10]$ & $0.81[0.66-0.94]$ & 0.003 \\
\hline Trunk fat/ total limb fat (\%) & $1.0[0.8-1.0]$ & $0.9[0.7-1.0]$ & 0.045 & $0.93[0.85-1.03]$ & $0.85[0.72-0.97]$ & 0.003 \\
\hline
\end{tabular}

*based on patient report, those with moderate or severe fat loss in 2 or more regions.

**Wilcoxon Rank-sum (Mann-Whitney) tests for continuous variables and chi-square tests for binary variables.

***based on patient report, those with moderate or severe fat gain in 2 or more regions. 


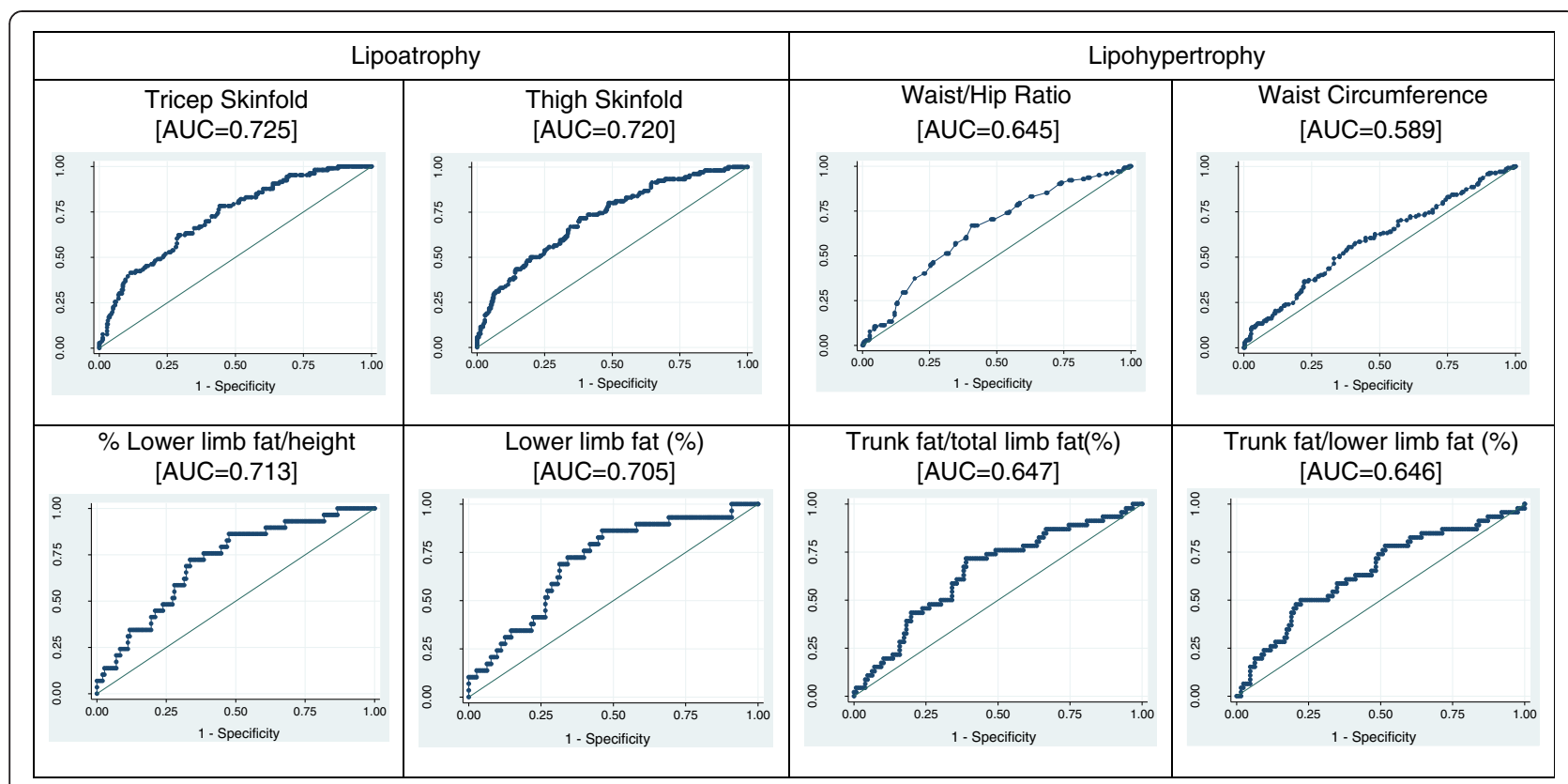

Figure 1 ROC curves for the 2 anthropometric and DXA-derived variables with the highest AUC for lipoatrophy and lipohypertrophy in female participants on ART.

two ART regimens were available to South Africans accessing primary health care facilities. The first-line regimen consisted of $\mathrm{d} 4 \mathrm{~T}$, lamivudine (3TC) and efavirenz (EFV) or nevirapine, and a second-line regimen consisting of AZT with 3TC and lopinavir/ritonavir (LPV/r) [35].

\section{Testing procedures}

Questionnaires were used to collect socio-demographic information from participants. Their clinical records at the health facilities were reviewed to obtain data on ART regimen, time on ART, and CD4 count. Self-reported information on fat gain or fat loss was collected using a standard questionnaire [8]. Lipoatrophy was defined as moderate or severe fat loss in 2 or more regions and lipohypertrophy defined as moderate or severe fat gain in two or more areas [36].

Anthropometric measurements: [weight, height, circumferences (waist, hip, mid-upper arm, and mid-thigh),

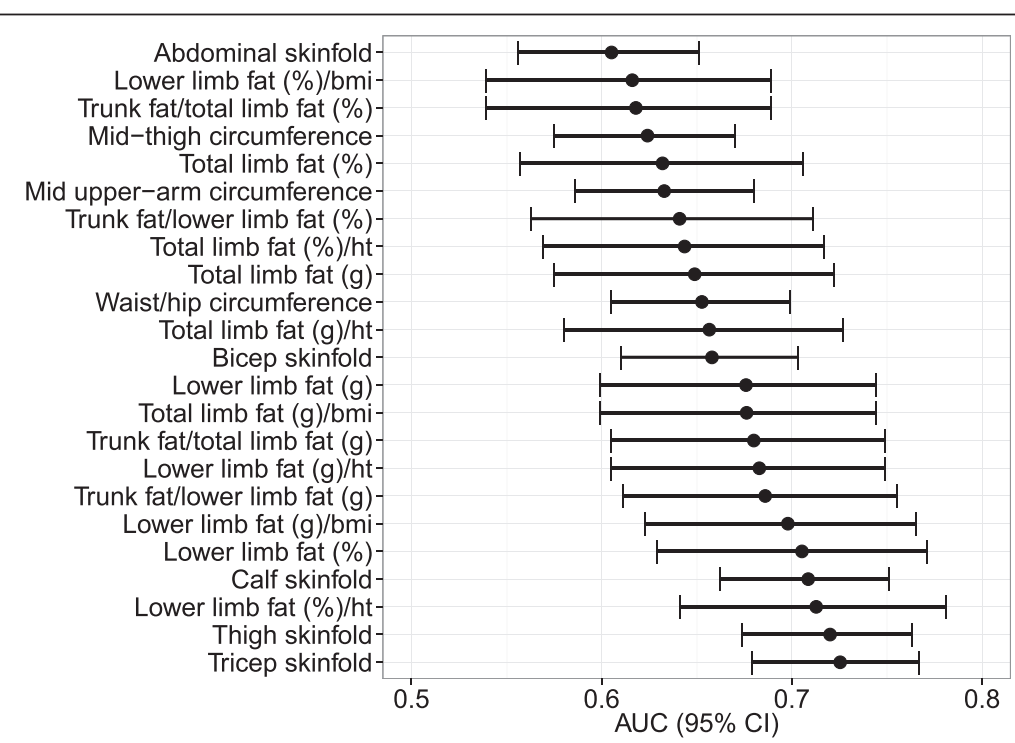

Figure 2 Lipoatrophy variables for female participants on ART with ROC AUCs of $\geq 0.6$ and their $95 \%$ confidence intervals in descending order of AUC. 
Table 5 Variables for prediction and classification used to identify lipoatrophy and lipohypertrophy cut-points

\begin{tabular}{|c|c|c|c|c|c|c|c|c|}
\hline Lipoatrophy variable cut-point & $\mathrm{N}$ & Sensitivity & Specificity & $\begin{array}{l}\text { Likelihood ratio } \\
\text { positive test }\end{array}$ & $\begin{array}{l}\text { Likelihood ratio } \\
\text { negative test }\end{array}$ & $\begin{array}{c}\text { Positive } \\
\text { predictive value }\end{array}$ & $\begin{array}{c}\text { Negative } \\
\text { predictive value }\end{array}$ & $\begin{array}{l}\% \text { correctly } \\
\text { classified }\end{array}$ \\
\hline Tricep skinfold $\leq 14.5 \mathrm{~mm}$ & 418 & 0.62 & 0.71 & 2.13 & 0.53 & 0.42 & 0.85 & $68.66^{*}$ \\
\hline Thigh skinfold $\leq 28.0 \mathrm{~mm}$ & 417 & 0.67 & 0.65 & 1.93 & 0.51 & 0.39 & 0.85 & $65.70^{*}$ \\
\hline \% Lower limb fat/height $\leq 24.7$ & 418 & 0.19 & 0.85 & 1.28 & 0.95 & 0.30 & 0.76 & $68.42^{*}$ \\
\hline Lower limb fat $(\%) \leq 39.1$ & 418 & 0.19 & 0.84 & 1.20 & 0.96 & 0.29 & 0.75 & $67.70^{*}$ \\
\hline \multicolumn{9}{|l|}{ Lipohypertrophy variable cut-point } \\
\hline Waist/Hip Ratio $\geq 0.899$ & 434 & 0.44 & 0.75 & 1.75 & 0.75 & 0.46 & 0.73 & $64.75^{* *}$ \\
\hline Waist Circumference $\geq 88.5 \mathrm{~cm}$ & 434 & 0.57 & 0.59 & 1.40 & 0.73 & 0.41 & 0.73 & $58.53^{* *}$ \\
\hline Trunk fat/total limb fat (\%) $\geq 0.8895$ & 172 & 0.50 & 0.70 & 1.66 & 0.72 & 0.38 & 0.79 & $64.5^{* *}$ \\
\hline Trunk fat/leg fat (\%) $\geq 0.8816$ & 172 & 0.72 & 0.61 & 1.84 & 0.46 & 0.40 & 0.86 & $64.0^{* *}$ \\
\hline
\end{tabular}

*percentage of those classified with and without lipoatrophy using the new cut-point compared to those defined by subject-report.

**percentage of those classified with and without lipohypertrophy using the new cut-point compared to those defined by subject-report. 
skinfold thickness (bicep, tricep, subscapular, abdomen, suprailiac, thigh and calf) and sagittal abdominal diameter (SAD)] taken have previously been described [37]. DXA (Hologic Discovery-W, software version 12.7; scan region $195 \times 65 \mathrm{~cm}^{2}$ and weight limit $160 \mathrm{~kg}$ ) was used to measure fat mass and fat free soft tissue mass in a subsample of participants (females: $\mathrm{n}=172$; males: $\mathrm{n}=$ 53). DXA cut off lines positioned at anatomical markers were used to obtain fat mass for the whole body as well as for the various regions of interest. A more detailed description has been previously described [34].

\section{Ethical approval}

The study proposal was submitted and approved by the Research Ethics Committee of the Faculty of Health Sciences at the University of Cape Town. Written informed consent was obtained from all participants prior to participation in the study.

\section{Data analyses}

Data analysis was carried out using the STATA/SE statistical software package version 12.0 (StataCorp., College Station, TX, USA). Data were collected between February 2007 and June 2009. Participants were categorised into those with and those without lipoatrophy. Continuous variables were described as medians and inter-quartile ranges (IQR), and were compared using Wilcoxon Rank Sum tests. Binary variables were described using chi-square tests.

Receiver operating characteristic (ROC) curves were used to describe the performance of a number of anthropometric and DXA-derived variables using patient reported lipoatrophy and lipohypertrophy as the reference standard. The area under the curve (AUC) was used to assess the diagnostic performance of each variable. In addition, sensitivity, specificity, likelihood ratios and predictive values were calculated for variables with the highest AUC at the optimum cut-points. Cut-point selection was based on positive likelihood ratios.

\section{Competing interests}

Supported by grants from the World Diabetes Foundation and the South African Department of Health. GM was supported in part by the National Research Foundation (NRF) of South Africa (grant specific unique reference number (UID) 85810). The Grant holder acknowledges that opinions, findings and conclusions or recommendations expressed in any publication generated by the NRF supported research are that of the author(s), and that the NRF accepts no liability whatsoever in this regard.

\section{Authors' contributions}

ZA conducted all statistical analyses, interpreted the findings and drafted the manuscript; JD, NL and GM designed and conducted the study; ML assisted with study design and data interpretation; $\mathrm{NL}, \mathrm{GM}$, JD and ML edited the manuscript and drafted revisions. All authors read and approved the manuscript.

\section{Acknowledgements}

We thank Linda Bewerunge for doing the DXA scans, Sasha West for anthropometric measurements, and Carmen Delport for co-ordinating the study.

\section{Author details}

'Division of Diabetic Medicine and Endocrinology, Department of Medicine, University of Cape Town, Cape Town, South Africa. ${ }^{2}$ Division of Clinical Pharmacology, Department of Medicine, University of Cape Town, Cape Town, South Africa. ${ }^{3}$ Department of Medicine, University of Cape Town, Cape Town, South Africa.

Received: 14 May 2014 Accepted: 21 July 2014

Published: 4 August 2014

\section{References}

1. Johnson LF: Access to antiretroviral treatment in South Africa, 2004-2011. SA J HIV Med 2012, 13(1):22-27.

2. Schambelan M, Benson CA, Carr A, Currier JS, Dubé MP, Gerber JG, Grinspoon SK, Grunfeld C, Kotler DP, Mulligan K: Management of metabolic complications associated with antiretroviral therapy for HIV-1 infection: recommendations of an International AIDS Society-USA panel. J Acquir Immune Defic Syndr 2002, 31(3):257-275.

3. Grinspoon S, Carr A: Cardiovascular risk and body-fat abnormalities in HIV-infected adults. N Engl J Med 2005, 352(1):48-62.

4. Carr A: HIV protease inhibitor-induced lipodystrophy syndrome. AIDS Rev 1999, 1:29-36.

5. Carter V, Hoy J, Bailey M, Colman P, Nyulasi I, Mijch A: The prevalence of lipodystrophy in an ambulant HIV-infected population: it all depends on the definition. HIV Med 2001, 2(3):174-180.

6. Casado JL, Iglesias V, Del Palacio M, Marín A, Perez-Elías MJ, Moreno A Moreno S: Social isolation in HIV-infected patients according to subjective patient assessment and DEXA-confirmed severity of lipodystrophy. AIDS Care 2013, 25(12):1599-1603.

7. Savès $M$, François $R$, Jacqueline $C$, Rozenbaum W, Ragnaud J, Perronne C, Basdevant A, Leport C, Geneviève C: Factors related to lipodystrophy and metabolic alterations in patients with human immunodeficiency virus infection receiving highly active antiretroviral therapy. Clin Infect Dis 2002, 34(10):1396-1405.

8. Carr A: An objective case definition of lipodystrophy in HIV-infected adults: a case-control study. Lancet 2003, 361(9359):726-735.

9. Worm D, Kirk O, Andersen O, Vinten J, Gerstoft J, Katzenstein T, Nielsen H, Pedersen C: Clinical lipoatrophy in HIV-1 patients on HAART is not associated with increased abdominal girth, hyperlipidaemia or glucose intolerance. HIV Med 2002, 3(4):239-246.

10. Sievers $M$, Walker U, Sevastianova K, Setzer B, Wågsäter D, Eriksson $P$, Yki-Järvinen H, Sutinen J: Gene expression and immunohistochemistry in adipose tissue of HIV type 1-infected patients with nucleoside analogue reverse-transcriptase inhibitor-associated lipoatrophy. J Infect Dis 2009, 200(2):252-262.

11. Menezes C, Maskew M, Sanne I, Crowther N, Raal F: A longitudinal study of stavudine-associated toxicities in a large cohort of South African HIV infected subjects. BMC Infect Dis 2011, 11(1):244.

12. McComsey GA, Kitch D, Sax PE, Tebas P, Tierney C, Jahed NC, Myers L, Melbourne K, Ha B, Daar ES: Peripheral and central fat changes in subjects randomized to abacavir-lamivudine or tenofovir-emtricitabine with atazanavir-ritonavir or efavirenz: ACTG Study A5224s. Clin Infect Dis 2011, 53(2):185-196.

13. Haubrich RH, Riddler SA, DiRienzo AG, Komarow L, Powderly WG, Klingman K Garren KW, Butcher DL, Rooney JF, Haas DW: Metabolic outcomes in a randomized trial of nucleoside, nonnucleoside and protease inhibitor-sparing regimens for initial HIV treatment. AIDS 2009, 23(9):1109

14. Valantin $\mathrm{M}$, Lanoy E, Bentata M, Kalmykova O, Boutekadjirt A, Allavena C, Rozenbaum W, Peytavin G, Amellal B, Calvez V: Recovery of fat following a switch to nucleoside reverse transcriptase inhibitor-sparing therapy in patients with lipoatrophy: results from the 96-week randomized ANRS 108 NoNuke Trial. HIV Med 2008, 9(8):625-635.

15. Asha HS, Seshadri MS, Paul TV, Abraham OC, Rupali P, Thomas N: Human immunodeficiency virus-associated lipodystrophy: an objective definition based on dual-energy $\mathrm{x}$-ray absorptiometry-derived regional fat ratios in a South Asian population. Endocr Pract 2012, 18(2):158-169.

16. Bonnet E, Delpierre C, Sommet A, Marion-Latard F, Herve R, Aquilina C, Labau E, Obadia M, Marchou B, Massip P: Total body composition by DXA of $241 \mathrm{HIV}$-negative men and $162 \mathrm{HIV}$-infected men: proposal of reference values for defining lipodystrophy. J Clin Densitom 2005, 8(3):287-292. 
17. Freitas P, Santos AC, Carvalho D, Pereira J, Marques R, Martinez E, Sarmento A Medina JL: Fat mass ratio: an objective tool to define lipodystrophy in hiv-infected patients under antiretroviral therapy. J Clin Densitom 2010 13(2):197-203.

18. Goedecke JH, Levitt NS, Lambert EV, Utzschneider KM, Faulenbach MV, Dave JA, West S, Victor H, Evans J, Olsson T: Differential effects of abdominal adipose tissue distribution on insulin sensitivity in black and white South African women. Obesity 2009, 17(8):1506-1512.

19. Kanaley J, Giannopoulou I, Tillapaugh-Fay G, Nappi J, Ploutz-Snyder L: Racial differences in subcutaneous and visceral fat distribution in postmenopausal black and white women. Metab Clin Exp 2003, 52(2):186-191.

20. Carroll JF, Chiapa AL, Rodriquez M, Phelps DR, Cardarelli KM, Vishwanatha JK, Bae S, Cardarelli R: Visceral fat, waist circumference, and BMl: impact of race/ethnicity. Obesity 2008, 16(3):600-607.

21. De Waal R, Cohen K, Maartens G: Systematic review of antiretroviral-associated lipodystrophy: lipoatrophy, but not central fat gain, is an antiretroviral adverse drug reaction. PLoS One 2013, 8(5):e63623.

22. Feleke $Y$, Fekade D, Mezegebu Y: Prevalence of highly active antiretroviral therapy associated metabolic abnormalities and lipodystrophy in HIV infected patients. Ethiop Med J 2012, 50(3):221-230.

23. World Health Organization: Global update on HIV treatment 2013: results, impact and opportunities. [http://www.who.int/hiv/pub/progressreports/ update2013/en/]

24. Freitas $P$, Carvalho D, Souto S, Santos AC, Xerinda S, Marques R, Martinez E, Sarmento A, Medina JL: Impact of Lipodystrophy on the prevalence and components of metabolic syndrome in HIV-infected patients. BMC Infect Dis 2011, 11(1):246

25. Masiá M, Padilla S, García N, Jarrin I, Bernal E, López N, Hernández I, Gutiérrez F: Endothelial function is impaired in HIV-infected patients with lipodystrophy. Antivir Ther 2010, 15(1):101-110.

26. Lake JE, Wohl D, Scherzer R, Grunfeld C, Tien PC, Sidney S, Currier JS: Regional fat deposition and cardiovascular risk in HIV infection: the FRAM study. AIDS Care 2011, 23(8):929-938.

27. Guaraldi G, Murri R, Orlando G, Giovanardi C, Squillace N, Vandelli M, Beghetto B, Nardini G, De Paola M, Esposito R: Severity of lipodystrophy is associated with decreased health-related quality of life. AIDS Patient Care STDS 2008, 22(7):577-585.

28. Huang JS, Harrity S, Lee D, Becerra K, Santos R, Mathews WC: Body image in women with HIV: a cross-sectional evaluation. AIDS Res Ther 2006, 3(17):1-7.

29. Tungsiripat M, O'Riordan MA, Storer N, Harrill D, Ganz J, Libutti D, Gerschenson M, McComsey GA: Subjective clinical lipoatrophy assessment correlates with DEXA-measured limb fat. HIV Clin Trials 2009, 10(5):314-319.

30. Van Oosterhout JJ, Mallewa J, Kaunda S, Chagoma N, Njalale Y, Kampira E, Mukaka M, Heyderman RS: Stavudine toxicity in adult longer-term ART patients in Blantyre. Malawi PLos One 2012, 7(7):e42029.

31. Bussmann H, Wester CW, Thomas A, Novitsky V, Okezie R, Muzenda T, Gaolathe T, Ndwapi N, Mawoko N, Widenfelt E, Moyo S, Musonda R, Mine M, Makhema J, Moffat H, Essex M, Degruttola V, Marlink RG: Response to zidovudine/didanosine-containing combination antiretroviral therapy among HIV-1 subtype C-infected adults in Botswana: two-year outcomes from a randomized clinical trial. J Acquir Immune Defic Syndr 2009, 51(1):37-46

32. Thompson V, Medard B, Taseera K, Chakera AJ, Andia I, Emenyonu N, Hunt PW, Martin J, Scherzer R, Weiser SD: Regional anthropometry changes in antiretroviral-naive persons initiating a Zidovudine-containing regimen in Mbarara. Uganda AIDS Res Hum Retroviruses 2011, 27(7):785-791.

33. George JA, Venter WD, Van Deventer HE, Crowther NJ: A longitudinal study of the changes in body fat and metabolic parameters in a South African population of HIV-positive patients receiving an antiretroviral therapeutic regimen containing stavudine. AIDS Res Hum Retroviruses 2009, 25(8):771-781.

34. Goedecke JH, Micklesfield LK, Levitt NS, Lambert EV, West S, Maartens G, Dave JA: Effect of different antiretroviral drug regimens on body fat distribution of HIV-infected South African women. AIDS Res Hum Retroviruses 2013, 29(3):557-563.

35. Department of Health: The South African antiretroviral treatment guidelines. [http://www.auruminstitute.org/phocadownload/guidelinesshort.pdf]
36. Lichtenstein KA, Ward DJ, Moorman AC, Delaney KM, Young B, Palella FJ Jr, Rhodes PH, Wood KC, Holmberg SD: Clinical assessment of HIV-associated lipodystrophy in an ambulatory population. AIDS 2001, 15(11):1389-1398.

37. Dave JA, Lambert EV, Badri M, West S, Maartens G, Levitt NS: Effect of nonnucleoside reverse transcriptase inhibitor-based antiretroviral therapy on dysglycemia and insulin sensitivity in South African HIV-infected patients. J Acquir Immune Defic Syndr 2011, 57(4):284-289.

doi:10.1186/1742-6405-11-26

Cite this article as: Abrahams et al:: The development of simple anthropometric measures to diagnose antiretroviral therapy-associated lipodystrophy in resource limited settings. AIDS Research and Therapy 2014 11:26.

\section{Submit your next manuscript to BioMed Central and take full advantage of:}

- Convenient online submission

- Thorough peer review

- No space constraints or color figure charges

- Immediate publication on acceptance

- Inclusion in PubMed, CAS, Scopus and Google Scholar

- Research which is freely available for redistribution 